\title{
Experiences of neurological surgeons with malpractice lawsuits
}

\author{
Pravesh S. Gadjradj, MD,1 Julian B. Ghobrial, BSc, ${ }^{1}$ and Biswadjiet S. Harhangi, MD, PhD, MSc² \\ 1'Department of Neurosurgery, Leiden University Medical Center, University Neurosurgical Center Holland (UNCH), Leiden; and \\ 2Department of Neurosurgery, Erasmus MC: University Medical Center Rotterdam, The Netherlands
}

OBJECTIVE As a specialty that treats acute pathology and refractory pain, neurosurgery is at risk for high liability, making the practice of defensive medicine quite common. The extent to which the practice of defensive medicine is linked to experience with malpractice lawsuits remains unclear. The aims of this study were to clarify this by surveying neurosurgeons about the frequency of experiencing medical lawsuits and to show how neurosurgeons reflect on facing such lawsuits.

METHODS A survey consisting of 24 questions was distributed among members of the Congress of Neurological Surgeons. The survey consisted of four parts: 1) demographics of participants; 2) the way malpractice lawsuits affect the way respondents practice medicine; 3) experiences with medical malpractice lawsuits; and 4) the effect of the medical malpractice environment on one's own practice of medicine.

RESULTS There were a total of 490 survey respondents, $83.5 \%$ of whom were employed in the US. Of the respondents, $39.5 \%$ stated they were frequently or always concerned about being sued, and $77.4 \%$ stated their fear had led to a change in how they practice medicine. For $58.4 \%$, this change led to the practice of defensive medicine, while for others it led to more extensive documentation (14.3\%) and/or to referring or dropping complex cases (12.4\%).

Among the respondents, $80.9 \%$ at some time were named in a medical malpractice lawsuit and $12.3 \%$ more than 10 times. The main concerns expressed about being sued included losing confidence and practicing defensive medicine (17.8\%), personal assets being at risk (16.9\%), and being named in the National Practitioner Data Bank (15.6\%). Given the medical malpractice environment, $58.7 \%$ of respondents considered referring complex patient cases, whereas $36.5 \%$ considered leaving the practice of medicine. The fear of being sued (OR 4.06, 95\% Cl 2.53-6.51) and the consideration of limiting the scope of practice (OR 3.08, 1.80-5.20) were both independently associated with higher odds of considering leaving the practice of medicine.

CONCLUSIONS The current medicolegal landscape has a profound impact on neurosurgical practice. The fear of being sued, the financial aspects of practicing defensive medicine, and the proportion of neurosurgeons who are considering leaving the practice of medicine emphasize the need for a shift in the medicolegal landscape to a system in which fear of being sued does not play a dominant role and the interests of patients are protected.

https://thejns.org/doi/abs/10.3171/2020.8.FOCUS20250

KEYWORDS medical lawsuit; liability; medical malpractice

$\mathrm{M}$ ANY healthcare professionals throughout the world face issues surrounding medical malpractice at some point in their careers. Unfortunately, a number of these cases turn into medical malpractice lawsuits. In particular, specialists working in medical fields at risk for high liability, such as cardiothoracic or vascular surgery and other surgical specialties, may find themselves in a courtroom facing a medical malpractice case. ${ }^{1}$ Medical malpractice lawsuits and the medical liability system aim to deter negligence by physicians, compensate patients who are negatively affected by such negligence, and promote corrective justice. ${ }^{2,3}$ For physicians, these lawsuits are not only costly and time intensive, but also emotionally challenging and often do not serve the purpose intended by the tort system. 4,5

A review of the literature shows that malpractice lawsuits may have a profound impact on physicians. Due to fear of legal repercussions, physicians may be more inclined to practice defensive medicine, basing their decisions on legal rather than medical standards..$^{6,7}$ This form of practicing medicine may stimulate physicians to perform unnecessary, additional therapeutic or diagnostic in- 
terventions that do not improve the medical condition of the patient (also referred to as positive defensive medicine), or it may cause physicians to refer or refuse difficult cases (also referred to as negative defensive medicine). ${ }^{6,8}$ Moreover, physicians may experience a change in the doctorpatient relationship, now viewing the patient as someone who should be approached with wariness and caution. ${ }^{9}$

As a specialty that treats acute pathology and refractory pain, neurosurgery is at risk for high liability. Because of this, the practice of defensive medicine is quite common. ${ }^{8,10,11}$ Previous research among neurosurgeons in Europe and the US showed that neurosurgeons may practice defensive medicine more frequently when the risk of medical malpractice lawsuits is greater. ${ }^{8,12}$ It is, however, unclear to what extent this is correlated with having faced malpractice suits and to what extent this has influenced their practice of medicine. Therefore, the goals of the current study were to survey the frequency with which neurosurgeons face medical malpractice lawsuits, discover how neurosurgeons reflect on facing lawsuits, and analyze outcomes of faced lawsuits.

\section{Methods}

\section{The Survey}

Based on the existing literature, ${ }^{6,13-15}$ a questionnaire was developed consisting of 24 questions divided into four main parts:

1) Demographics of participants. This section sought the following information: the participant's function in the neurosurgical field, neurosurgical subspecialty, clinical experience in years, country of employment, and costs of medical malpractice insurance, and whether the respondent fears being sued in daily practice.

2) The ways that fear of malpractice lawsuits affects how respondents practice medicine and view their patients. This section consisted of three questions regarding whether respondents believed that the risk of being sued has changed the way they practice medicine, in what way respondents' medical practices have changed, and how these changes affect their patients.

3) Respondents' personal experiences with medical malpractice lawsuits. This section consisted of 10 questions mainly centered around respondents' experiences with medical malpractice lawsuits, outcomes of these lawsuits, and the amount of time and money respondents spent on these lawsuits.

4) Effect of the medical malpractice environment on respondents' personal practice of medicine. This section consisted of five questions regarding whether respondents had considered referring difficult cases, to what extent respondents had limited the scope of offered procedures and services, how they assess the malpractice legal process in their country of origin, and, finally, if they have considered leaving the practice of medicine in its entirety.

\section{Distribution}

The member directory of the Congress of Neurological Surgeons (CNS) was queried to identify neurosurgeons and neurosurgeons in training. Of the 9007 entries in the member directory, 8457 email addresses were available. These email addresses were entered into SurveyMonkey, and in March 2020 CNS members were invited to take the survey. Three reminders were sent to recipients to increase the response rate. The questionnaire was filled out by respondents between March 2020 and May 2020.

\section{Statistical Analysis}

Answers to the survey were imported to SPSS for Windows version 24 (IBM Corp.) for analysis purposes. The data were checked for uniformity and adapted where necessary to ensure that an adequate analysis was possible. Valid percentages were used to demonstrate frequencies. For analyzing purposes, a seven-point Likert scale on fear of being sued was dichotomized with "frequently" and "always" in one category and the remaining five options in another. To identify factors related to considering leaving the field of medicine, multivariate logistic regression was used to calculate odds ratios (ORs) with their respective 95\% confidence intervals (CIs). Statistical significance was set at $\mathrm{p}<0.05$.

\section{Results}

In total, 6115 surveys were sent, of which 3580 were opened by recipients. Eventually, 490 responses were received, leading to a response rate of $8.0 \%$.

\section{Demographics of the Participants}

Table 1 provides an overview of respondents' demographics. Most respondents were employed as neurosurgeons (92.2\%), while 5.1\% were residents. Overall, the respondents had a mean \pm SD clinical experience of 25.1 \pm 12.7 years. Spine $(65.5 \%)$, neuro-oncology $(36.7 \%)$, and neurotrauma (36.7\%) were the largest subspecialty fields of respondents. The vast majority of respondents (83.5\%) were employed in the US (Fig. 1).

When asked about the costs of medical malpractice insurance, $60.8 \%$ of respondents were aware of the actual amount of the costs. Almost one-fifth had insurance costs ranging in US currency from $\$ 100,000$ to $\$ 500,000$, whereas costs exceeded $\$ 500,000$ for $8.1 \%$. When asked about the fear of being sued, 39.5\% of respondents stated they were frequently or always concerned about the risk of being sued. For $77.4 \%$, fear of being sued had changed the way they practice medicine. Neurosurgeons who were unconcerned by the risk of being sued did not differ in continent of employment, clinical experience, or subspecialization compared with those who were concerned about the risk of being sued.

\section{Way in Which Fear of Malpractice Lawsuits Affected the Way Respondents Practice Medicine and Care for Their Patients}

Table 2 shows how fear of being sued had affected medical practice and patient care according to respondents. Most respondents (58.4\%) mentioned the practice of defensive medicine, which mainly includes ordering more tests, even if they are not deemed necessary. Extensive documentation while consulting patients (14.3\%) 
TABLE 1. Demographics of respondents

\begin{tabular}{|c|c|}
\hline & No. $(\%)$ \\
\hline No. of respondents & 490 \\
\hline \multicolumn{2}{|l|}{ Professional function } \\
\hline Neurosurgeon & $452(92.2)$ \\
\hline Neurosurgeon in training & $25(5.1)$ \\
\hline Other & $13(2.7)$ \\
\hline \multicolumn{2}{|l|}{ Specialty* } \\
\hline Epilepsy & $30(6.1)$ \\
\hline Functional & $50(10.2)$ \\
\hline General neurosurgery & $29(5.9)$ \\
\hline Peripheral nerve & $61(12.4)$ \\
\hline Pediatrics & $71(14.5)$ \\
\hline Neuro-oncology & $180(36.7)$ \\
\hline Neurovascular & $103(21.0)$ \\
\hline Neurotrauma & $180(36.7)$ \\
\hline Skull base & $13(2.7)$ \\
\hline Spine & $321(65.5)$ \\
\hline Other & $17(3.5)$ \\
\hline \multicolumn{2}{|l|}{ Yrs of clinical experience } \\
\hline$\leq 5$ & $23(4.7)$ \\
\hline $6-10$ & $51(10.4)$ \\
\hline $11-20$ & $127(25.9)$ \\
\hline$>20$ & $289(59.0)$ \\
\hline \multicolumn{2}{|l|}{ Continent of employment } \\
\hline Africa & $5(1.0)$ \\
\hline Asia \& Oceania & $28(5.7)$ \\
\hline Europe & $29(5.9)$ \\
\hline North America & $422(86.1)$ \\
\hline South America & $6(1.2)$ \\
\hline \multicolumn{2}{|c|}{ Cost of medical malpractice insurance $(n=298)$} \\
\hline$<\$ 5,000$ & $53(17.8)$ \\
\hline$\$ 5,000-\$ 10,000$ & $5(1.7)$ \\
\hline$\$ 10,000-\$ 100,000$ & $158(53.0)$ \\
\hline$\$ 100,000-\$ 500,000$ & $58(19.5)$ \\
\hline$>\$ 500,000$ & $24(8.1)$ \\
\hline \multicolumn{2}{|l|}{ Fear of being sued $(n=456)$} \\
\hline Never think about it & $13(2.9)$ \\
\hline Rarely crosses my mind & $46(10.1)$ \\
\hline Not very concerned & $46(10.1)$ \\
\hline Moderate & $54(11.8)$ \\
\hline Occasionally concerned & $117(25.7)$ \\
\hline Frequently concerned & $84(18.4)$ \\
\hline Always concerned & $96(21.1)$ \\
\hline \multicolumn{2}{|c|}{$\begin{array}{l}\text { Risk of being sued has changed the way in which I } \\
\text { practice medicine }(n=456)\end{array}$} \\
\hline Yes & $353(77.4)$ \\
\hline No & $103(22.6)$ \\
\hline
\end{tabular}

${ }^{*}$ Multiple answers were possible. and referring or dropping certain complex cases (12.4\%) were also frequently mentioned. Of all respondents, 5.9\% believed that fear of being sued positively affects patient care, while $18.0 \%$ believed that patient care is not affected at all. Most respondents (24.8\%), however, mentioned that fear of being sued only results in more costs for both the patient and healthcare in general.

\section{Personal Experience With Medical Malpractice Lawsuits}

Considering their entire careers, $80.9 \%$ of respondents stated that they had been named in a medical malpractice lawsuit; $25.8 \%$ had been involved in one malpractice lawsuit, while $12.3 \%$ had been involved in more than 10 lawsuits. The main concerns about being sued are listed in Table 3. Losing confidence and practicing defensive medicine were mentioned most often (17.8\%), followed by personal assets being at risk (16.9\%) and being named in the National Practitioner Data Bank (15.6\%). When asked about the outcome of medical malpractice lawsuits, most frequently responders stated that the lawsuit had been dropped (34.5\%) or settled with payout to the plaintiff without going to trial (22.4\%). In cases in which there had been a settlement or verdict in court, the payout had exceeded $\$ 1,000,000$ according to $15.0 \%$ of respondents. Considering all involved lawsuits, $19.2 \%$ of respondents believed that the patient deserved compensation. The impact of the medical malpractice environment is shown in Table 4.

\section{Effect of the Medical Malpractice Environment on the Practice of Medicine}

Due to the medical malpractice environment, $58.7 \%$ of respondents considered referring difficult patient cases, while $61.4 \%$ considered limiting the scope of the procedures offered. Overall, $36.5 \%$ of respondents considered leaving medical practice due to the legal landscape. Multivariable logistic regression analysis (Table 5) shows that fear of being sued (OR 4.06, 95\% CI 2.53-6.51) and considering limiting the scope of medical practice (OR 3.08, 95\% CI 1.80-5.20) were both independently associated with higher odds of considering leaving the practice of medicine. Clinical experience longer than 15 years, being employed in the US, and having been named in a malpractice suit at some time were not associated with considering leaving the practice of medicine.

\section{Discussion}

The goals of the current study were to determine the proportion of neurosurgeons who had faced medical malpractice lawsuits and to assess how being named in malpractice lawsuits has influenced the practice of medicine. Four hundred ninety members of the CNS responded, mostly neurosurgeons employed in the US. One of five respondents claimed always being concerned about being sued, and for $77.4 \%$ this fear led to a change in how respondents practice medicine, mostly a switch to practicing defensive medicine. Due to the medical malpractice environment, more than half of the respondents considered referring complex cases or limiting the scope of procedures offered. Overall, more than one-third of respondents had considered leaving the practice of medicine. 

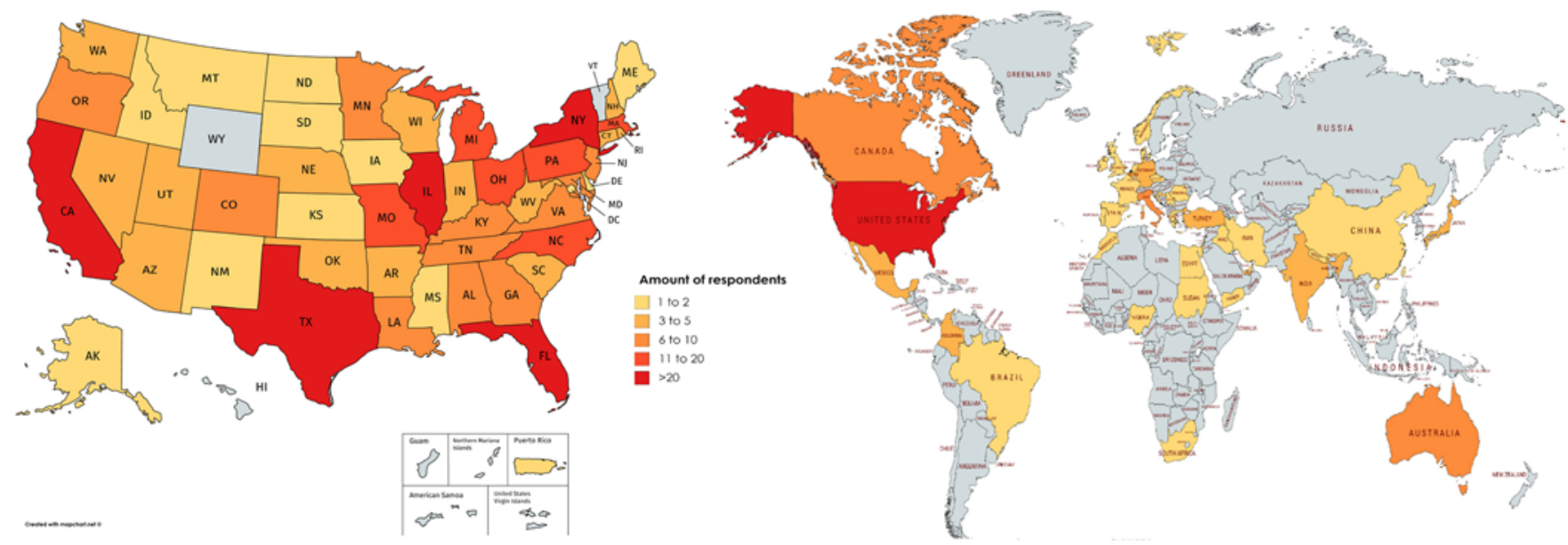

FIG. 1. Geographic overview of respondents' working locations. Created using mapchart.net. CC BY-SA 4.0 (https:// creativecommons.org/licenses/by-sa/4.0/).

\section{Comparison With Other Studies}

The results of prior studies have shown that a switch in practice to defensive medicine after encountering medical malpractice lawsuits is common. Studdert et al. studied the prevalence of defensive medicine among physicians employed in general surgery, neurosurgery, orthopedic surgery, obstetrics-gynecology, and radiology in $2003 .^{6}$ They found a higher rate of physicians practicing defensive medicine $(93 \%)$ due to the threat of malpractice liability. Of their respondents, $42 \%$ had taken steps to restrict their practices, as compared with $61.4 \%$ in our study who considered limiting the scope of practice. Similar results were also seen in more recent surveys focused on practicing defensive medicine in the neurosurgical field. ${ }^{8,11,12}$

In the study by Smith et al., neurosurgeons in the US were $50 \%$ more likely to practice defensive medicine in states categorized as high-risk liability environments than in states categorized as low-risk liability environments. ${ }^{12}$ Another survey among US neurosurgeons showed that neurosurgeons who mainly practice spine surgery were up to three times more likely to practice defensive medicine than other neurosurgeons. ${ }^{11}$ In contrast to earlier studies in which neurosurgeons employed in the US had been surveyed, Yan et al. explored defensive medicine behaviors among Dutch neurosurgeons. ${ }^{8}$ Their study showed that Dutch neurosurgeons viewed their practices to be less at risk in general compared to their American colleagues. In our study, we could not identify differences in practicing defensive medicine, the fear of being sued, or considering leaving the practice of medicine between neurosurgeons employed in the US and neurosurgeons employed elsewhere.

In our survey, spinal surgery was the most frequently named specialty involved in medical malpractice lawsuits. In a recent retrospective analysis of malpractice claims filed in a large area of Germany encompassing 10 million inhabitants, cases related to spinal surgery were analyzed. ${ }^{16}$ Of the 8381 malpractice claim cases filed between 2012 and 2016 that were reviewed, 340 (4\%) were related to patients undergoing spinal surgery. In 89 cases (26.2\%), actual treatment errors were found, of which $91.0 \%$ re- sulted in patients' health deterioration. Degenerative disc disease $(41.9 \%)$, spinal canal stenosis $(16 \%)$, vertebral body fractures (12.3\%), and spondylolisthesis (7.4\%) were the most common diagnoses treated in these cases. Aside from misplaced pedicle screws and nerve root injury, surgeon errors also included pressure ulcers, performing more extensive procedures without informed consent, and performing an unsuitable surgical approach for a disc herniation. This finding indicates that noncomplex spinal surgeries, such as laminectomies or discectomies, also carry a high risk of medical liability and that referring complex procedures may not necessarily lead to an actual decrease in the risk of being named in a lawsuit. The results of a retrospective analysis of spine-related malpractice litigation cases in the US are in line with these findings, showing that $37.7 \%$ of all spine surgery malpractice cases are related to decompressions. ${ }^{17}$

Thomas et al. analyzed 343 cases filed between 1985 and 2015 that were related to medical malpractice and neurosurgery by using a comprehensive database for legal information in the US. ${ }^{18}$ Among these cases, most were related to spine procedures (58.0\%), which is in line with the experiences of our respondents. In the US database, general neurosurgery (15.8\%), cerebrovascular surgery (11.1\%), and oncological neurosurgery $(7.3 \%)$ were other frequently involved subfields. The most common bases of the allegations were procedural errors, failure to treat, and failure to diagnose. Median payout awards for these were $\$ 1,594,577, \$ 2,000,000$, and $\$ 2,100,000$, respectively. Thomas et al. also looked at the chronological distribution of cases and showed an increase in the number of cases between 1985 and 2009, followed by a decline in the number of cases up until 2015. From this we may infer the start of a change in the medical landscape.

\section{Possible Solutions}

It is clear that the medicolegal landscape has a profound and often severe impact on neurosurgeons with high-risk practices as well as on their patients. Addressing issues of the current medical malpractice environment is therefore 
TABLE 2. Frequent answers on ways in which fear of being sued had changed practice and affected patients

\begin{tabular}{cc}
\hline & No. $(\%)$ \\
\hline Ways in which medical practice has changed $(\mathrm{n}=322)$ & $11(3.4)$ \\
\hline No change & $188(58.4)$ \\
\hline Practice more defensive medicine by more testing & $46(14.3)$ \\
\hline More documentation & $40(12.4)$ \\
\hline Drop certain cases/refer certain complex cases & $58(18.0)$ \\
\hline Ways in which this affects patients $(\mathrm{n}=322)$ & $42(13.0)$ \\
\hline Does not affect patients & $80(24.8)$ \\
\hline Undergo needless tests \& procedures & $23(7.1)$ \\
\hline Increased costs & $19(5.9)$ \\
\hline Disturbed physician-patient relationship
\end{tabular}

Ways in which medical practice has changed

"Thinking of how people tend to expect that a perfect result is the norm and anything less than perfect is malpractice, even though this couldn't be further from the truth. There are unrealistic expectations out there and when things don't turn out in their favor, this has the potential to generate a lawsuit. Therefore, I have stressed realistic expectations up front more than I had in the past in order to make a positive change so the expectations are understood as much as possible ahead of time."

"I started to select patients based on likelihood of being sued. I installed protective programs that minimize a chance of being sued, such as videos of preop visits. This raised my overhead significantly."

"I have stopped doing high-risk adult deformity surgery. I perform much less surgery now. Every interaction is seen as a potential litigation. Being on call is torture. ... I no longer enjoy being a neurosurgeon."

"I treat the patient as a human being first, second as a disease process/challenge and third regardless of anything as a potential plaintiff."

"Have to practice in constant fear of lawyers and those not trained to be clinicians analyzing every decision."

Ways in which aforementioned changes affect patients

"It gives them realistic expectations of what they should expect. Also, gives them liability in their own care. I.e., if they are smokers, obese, DM, opioid dependent, they must understand that 'poor outcomes' are not necessarily due to technical deficiencies from surgery but that they have a role in their own outcome as well."

"Patients are nearly uniformly adversarial. Expectations are unreasonable. Their Google search holds more weight than my recommendations. Any complication or less than perfect outcome is considered malpractice."

"There is always a certain lack of trust despite extra efforts to maintain empathy and provide transparency and extensive explanation of their condition and treatment options."

"They appreciate the honesty and many are surprised to understand the realistic expectations are not what they thought when they came into the office or hospital initially."

"Usually result in helping patient by patient being better informed and surgeon better equipped not to harm patient."

$\mathrm{DM}=$ diabetic.

Not all answers could be categorized.

important, because it ensures that patients will continue to have access to high-risk care while also protecting the health professional who performs a high-risk procedure. A possible solution is the implementation of a system in which healthcare organizations provide transparent communication with patients in the case of adverse events. Another solution could be the use of informed consent forms. ${ }^{19}$ Informed consent, documented or not, however, is limited by the health literacy of the patients undergoing surgery. ${ }^{20}$ Additionally, healthcare organizations would have to invest in rapid investigation of adverse events and fair compensation for the patient in the case of an adverse event. ${ }^{3,21}$ Such a program would result in a greater number of plaintiffs receiving compensation for cases of true negligence and fewer plaintiffs receiving compensation for injuries that are not a result of negligence. ${ }^{22}$ Another possible solution is the implementation of health courts, which consist of disciplinary judges with a medical background. These health courts would be more capable of discerning between adverse effects due to true negligence and adverse effects due to the nature of high-risk procedures..$^{10,23}$

\section{Strengths and Limitations}

This study contains some limitations that have to be acknowledged. First, our method of data collection, by survey, constitutes a retrospective study, and respondents with more recent experiences with medical malpractice lawsuits may be better able to recall relevant events than respondents with less recent experiences. Second, medical malpractice cases can often be emotionally challenging and tough to 
TABLE 3. Experience with malpractice suits

\begin{tabular}{|c|c|}
\hline & No. $(\%)$ \\
\hline \multicolumn{2}{|l|}{ Named in a medical malpractice lawsuit $(n=419)$} \\
\hline Yes & $339(80.9)$ \\
\hline No & 80 (19.1) \\
\hline \multicolumn{2}{|l|}{ Main concern about being sued $(n=326)$} \\
\hline Reputation among peers & $31(9.5)$ \\
\hline Cost of malpractice insurance & $38(11.7)$ \\
\hline Personal assets at risk & $55(16.9)$ \\
\hline Impact on "inflicted" patient & $20(6.1)$ \\
\hline Losing confidence \& practicing defensive medicine & $58(17.8)$ \\
\hline Impact on the overall healthcare system & $33(10.1)$ \\
\hline Being named in the National Practitioner Data Bank & $51(15.6)$ \\
\hline Unfavorable publicity in the media & $8(2.5)$ \\
\hline Other & $32(9.8)$ \\
\hline \multicolumn{2}{|l|}{ No. of medical malpractice lawsuits $(n=325)$} \\
\hline 1 & $84(25.8)$ \\
\hline 2 & $71(21.8)$ \\
\hline 3 & $64(19.7)$ \\
\hline 4 & $13(4.0)$ \\
\hline 5 & $25(7.7)$ \\
\hline Other & $68(20.9)$ \\
\hline \multicolumn{2}{|l|}{ Outcome of medical malpractice lawsuits* } \\
\hline Lawsuit was dropped & $169(34.5)$ \\
\hline Case was settled w/ payout to plaintiff & $110(22.4)$ \\
\hline Case was settled w/o payout to plaintiff & $21(4.3)$ \\
\hline Case went to trial w/ plaintiff verdict & $14(2.9)$ \\
\hline Case went to trial w/ defendant verdict & $53(10.8)$ \\
\hline Other & $62(12.7)$ \\
\hline \multicolumn{2}{|l|}{$\begin{array}{l}\text { Neurosurgical fields involved in medical malpractice } \\
\text { lawsuits* }\end{array}$} \\
\hline Functional & $13(2.7)$ \\
\hline Peripheral nerve & $12(2.4)$ \\
\hline Pediatrics & $20(4.1)$ \\
\hline Neuro-oncology & $41(8.4)$ \\
\hline Neurovascular & $34(6.9)$ \\
\hline Neurotrauma & $48(9.8)$ \\
\hline Spine & $237(48.4)$ \\
\hline Other & $24(4.9)$ \\
\hline
\end{tabular}

Highest payout to plaintiff in case of settlement or verdict $(n=187)$

$\begin{array}{ll}<\$ 50,000 & 26(13.9) \\ \$ 50,000-\$ 150,000 & 38(20.3) \\ \$ 150,001-\$ 300,000 & 32(17.1) \\ \$ 300,001-\$ 600,000 & 25(13.4) \\ \$ 600,001-\$ 1,000,000 & 38(20.3) \\ >\$ 1,000,000 & 28(15.0)\end{array}$

Did the patient deserve compensation, according to your opinion? $(n=302)$

\begin{tabular}{lr} 
Yes & $58(19.2)$ \\
No & $244(80.8)$ \\
\hline
\end{tabular}

CONTINUED IN NEXT COLUMN »
» CONTINUED FROM PREVIOUS COLUMN

TABLE 3. Experience with malpractice suits

No. (\%)

No. of days spent defending medical malpractice

lawsuit $(n=278)$

\begin{tabular}{lc}
$<7$ & $68(24.5)$ \\
\hline $7-13$ & $51(18.3)$ \\
\hline $14-20$ & $55(19.8)$ \\
\hline $21-30$ & $49(17.6)$ \\
\hline $30-90$ & $28(10.1)$ \\
\hline $90-120$ & $3(1.1)$ \\
\hline$>120$ & $24(8.6)$ \\
\hline Personally liable for any associated costs $(n=328)$ & \\
\hline Yes & $32(9.8)$ \\
\hline No & $296(90.2)$ \\
\hline Cost of personal liability $(n=25)$ & $9(36.0)$ \\
\hline$<\$ 10,000$ & $10(40.0)$ \\
\hline$\$ 10,000-\$ 50,000$ & $1(4.0)$ \\
\hline$\$ 50,001-\$ 75,000$ & $2(8.0)$ \\
\hline$\$ 75,001-\$ 100,000$ & $3(12.0)$ \\
\hline$>\$ 100,000$ & \\
\hline
\end{tabular}

${ }^{*}$ Multiple answers were possible. Percentages relate to total respondents.

deal with for involved physicians. Therefore, respondents may have trouble answering the survey questions objectively. Moreover, our survey had a limited response rate of $8.0 \%$, which may negatively impact the quality of our conclusions. On the other hand, a review of the literature seems to indicate that a low response rate does not necessarily impact survey quality and the quality of conclusions that are drawn..$^{24}$ Furthermore, the literature indicates that

\section{TABLE 4. Impact of medical malpractice environment}

\begin{tabular}{lr}
\hline & No. $(\%)$ \\
\hline $\begin{array}{l}\text { Assessment of malpractice legal process in country of } \\
\text { origin }(n=399)\end{array}$ \\
\hline Heavily weighted to plaintiff & $131(32.8)$ \\
\hline Somewhat weighted to plaintiff & $149(37.3)$ \\
\hline Fair & $55(13.8)$ \\
\hline Somewhat weighted to defendant & $48(12.0)$ \\
\hline Heavily weighted to defendant & $16(4.0)$ \\
\hline Has considered referring difficult cases $(n=407)$ & \\
\hline Yes & $239(58.7)$ \\
\hline No & $168(41.3)$ \\
\hline Has considered limiting scope of offered procedures \& \\
services $(n=399)$ \\
\hline Yes & $245(61.4)$ \\
\hline No & $154(38.6)$ \\
\hline Considered leaving practice of medicine $(n=400)$ & $146(36.5)$ \\
\hline Yes & $254(63.5)$ \\
\hline No
\end{tabular}


TABLE 5. Multivariable logistic regression on parameters associated with fear of being sued and considering leaving the practice of medicine

\begin{tabular}{lcc}
\hline \multirow{2}{*}{\begin{tabular}{l} 
Variable \\
\cline { 2 - 3 }
\end{tabular}} & \multicolumn{2}{c}{$\begin{array}{c}\text { Considering Leaving the } \\
\text { Practice of Medicine }\end{array}$} \\
\cline { 2 - 3 } Clinical experience $>15$ yrs & OR & $95 \% \mathrm{Cl}$ \\
\hline Employed in US & 0.89 & $0.52-1.54$ \\
\hline Fear of being sued & 1.45 & $0.73-2.90$ \\
\hline Ever been named in a malpractice suit & 1.72 & $0.86-3.46$ \\
\hline $\begin{array}{l}\text { Considered limiting scope of } \\
\text { procedures offered }\end{array}$ & $3.08^{*}$ & $1.80-5.20$ \\
\hline
\end{tabular}

* Significant at $p<0.0001$

studies with larger response rates do not necessarily have lower levels of nonresponse bias. ${ }^{25}$ As no demographics of nonresponders were available, no formal nonresponse bias analysis could be conducted. Another limitation might lie in the interpretation of survey answers, which is partly demonstrated in Table 2. Given two open questions, a large variety of answers were received and could only partly be categorized. By demonstrating examples of open answers, we aimed to show the gist of responses to both questions.

\section{Conclusions}

The current medicolegal landscape has a profound impact on neurosurgical practice. The fear of being sued, the financial aspects of practicing defensive medicine, and the proportion of neurosurgeons who consider leaving the practice of medicine emphasize the need for a shift in the medicolegal landscape to a system in which the fear of being sued does not play a dominant role and the interests of patients are protected.

\section{References}

1. Jena AB, Seabury S, Lakdawalla D, Chandra A. Malpractice risk according to physician specialty. $N$ Engl J Med. 2011; 365(7):629-636.

2. Keeton WPDD, Keeton RE. Owen DC Prosser and Keeton on the Law of Torts. 5th ed. West Group; 1984.

3. Mello MM, Frakes MD, Blumenkranz E, Studdert DM. Malpractice liability and health care quality: a review. JAMA. 2020;323(4):352-366.

4. Studdert DM, Mello MM, Brennan TA. Medical malpractice. N Engl J Med. 2004;350(3):283-292.

5. Daniels AH, Ruttiman R, Eltorai AEM, et al. Malpractice litigation following spine surgery. J Neurosurg Spine. 2017; 27(4):470-475.

6. Studdert DM, Mello MM, Sage WM, et al. Defensive medicine among high-risk specialist physicians in a volatile malpractice environment. JAMA. 2005;293(21):2609-2617.

7. Kessler DP, Summerton N, Graham JR. Effects of the medical liability system in Australia, the UK, and the USA. Lancet. 2006;368(9531):240-246.

8. Yan SC, Hulsbergen AFC, Muskens IS, et al. Defensive medicine among neurosurgeons in the Netherlands: a national survey. Acta Neurochir (Wien). 2017;159(12):2341-2350.

9. Guillain A, Moncany AH, Hamel O, et al. Spine neurosurgeons facing the judicialization of their profession: disen- chantment and alteration of daily practice - a qualitative study. Acta Neurochir (Wien). 2020;162(6):1379-1387.

10. Nahed BV, Babu MA, Smith TR, Heary RF. Malpractice liability and defensive medicine: a national survey of neurosurgeons. PLoS One. 2012;7(6):e39237.

11. Din RS, Yan SC, Cote DJ, et al. Defensive medicine in U.S. spine neurosurgery. Spine (Phila Pa 1976). 2017;42(3):177-185.

12. Smith TR, Habib A, Rosenow JM, et al. Defensive medicine in neurosurgery: does state-level liability risk matter? Neurosurgery. 2015;76(2):105-114.

13. Sobel DL, Loughlin KR, Coogan CL. Medical malpractice liability in clinical urology: a survey of practicing urologists. J Urol. 2006;175(5):1847-1851.

14. Kaplan GW. Malpractice risks for urologists. Urology. 1998; 51(2):183-185.

15. Pereira NP, Lewin JS, Yousem KP, Yousem DM. Attitudes about medical malpractice: an American Society of Neuroradiology survey. AJNR Am J Neuroradiol. 2014;35(4):638-643.

16. Ahmadi SA, Sadat H, Scheufler KM, et al. Malpractice claims in spine surgery in Germany: a 5-year analysis. Spine J. 2019;19(7):1221-1231.

17. Agarwal N, Gupta R, Agarwal P, et al. Descriptive analysis of state and federal spine surgery malpractice litigation in the United States. Spine (Phila Pa 1976). 2018;43(14):984-990.

18. Thomas R, Gupta R, Griessenauer CJ, et al. Medical malpractice in neurosurgery: a comprehensive analysis. World Neurosurg. 2018;110:e552-e559.

19. Grady C. Enduring and emerging challenges of informed consent. N Engl J Med. 2015;372(22):2172.

20. Glassman SD, Carreon LY, Brown ME, et al. The impact of health literacy on health status and resource utilization in lumbar degenerative disease. Spine J. 2019;19(4):711-716.

21. Boothman RC, Blackwell AC, Campbell DA Jr, et al. A better approach to medical malpractice claims? The University of Michigan experience. J Health Life Sci Law. 2009;2(2): 125-159.

22. Helmchen LA, Richards MR, McDonald TB. How does routine disclosure of medical error affect patients' propensity to sue and their assessment of provider quality? Evidence from survey data. Med Care. 2010;48(11):955-961.

23. Scarrow AM. Tort reform: alternative models. Clin Neurosurg. 2008;55:121-125.

24. Livingston EH, Wislar JS. Minimum response rates for survey research. Arch Surg. 2012;147(2):110.

25. Davern M. Nonresponse rates are a problematic indicator of nonresponse bias in survey research. Health Serv Res. 2013; 48(3):905-912.

\section{Disclosures}

The authors report no conflict of interest concerning the materials or methods used in this study or the findings specified in this paper.

\section{Author Contributions}

Conception and design: Gadjradj. Acquisition of data: Gadjradj. Analysis and interpretation of data: Gadjradj, Ghobrial. Drafting the article: Gadjradj, Ghobrial. Critically revising the article: Ghobrial, Harhangi. Reviewed submitted version of manuscript: all authors. Approved the final version of the manuscript on behalf of all authors: Gadjradj. Statistical analysis: Gadjradj, Ghobrial. Administrative/technical/material support: all authors. Study supervision: Harhangi.

\section{Correspondence}

Pravesh S. Gadjradj: Leiden University Medical Center, Leiden, The Netherlands. p.gadjradj@erasmusmc.nl. 